\title{
The Relationship between Technology Usage and Marital Conflicts among Young Married Couples in Jimma Town
}

\author{
Daba Mekuria Benti ${ }^{1}$; Desalegn Garuma; Teshome Tena ${ }^{2}$ \\ ${ }^{1}$ Department of psychology, Wollega University, Ethiopia \\ ${ }^{2}$ Department of psychology, Jimma University, Ethiopia \\ http://dx.doi.org/10.18415/ijmmu.v5i6.677
}

\begin{abstract}
This study is conducted with the objective of investigating how technology usage causes marital conflict among married couples in Jimma town. The study employed mixed research design and collected data from 198 married couples that were randomly selected from the population. Data was collected using self-prepared questionnaire, standardized scales questionnaire and interview guide and analyzed using thematic data analysis method for qualitative data and quantitative data analysis method for quantitative once. The study found that technology usage was appropriate in marital relationship but only when the couples used technology in appropriate ways resulted in marital conflict. Among these technologies, Facebook, mobile usage and television watching statistically significant positive relationship with marital conflicts, $r=.788, r=.642$, and $r=.63$ respectively. The study also revealed that time spent on those technologies, issues of trust between couples, money and the time when couples have to use these technologies were the common causes of marital conflicts as a result of technology usages. In line with the findings obtained it was recommended that different organization such as welfare offices, NGOs and religious organizations should have to assign trained family and marriage counselors and social workers.
\end{abstract}

Keywords: Technology; Marital Conflict; Jimma Town

\section{Introduction}

Many married couples experience that their relationship changes over time. During the first years of the relationship, they had spent many evenings just talking with each other. But as the relationship progresses, the constraints of everyday life seem to take control of their marriage: technology, children, career, friends \& relatives, church, (all are very good in themselves), but in the end they became a burden for the marriage. Although marital conflict is inevitable in marriages due to the fact that couples are from different backgrounds, many factors have combined to affect the marriage institution. Now a day's technology plays fundamental roles in day to day activities of human beings. Technological revolution has intruded into couple life in subtle ways, where couples are not always aware of the changes that have emerged in their relationships (Leggett \& Rossouw, 2014). With the increasing use of technology to achieve social connection, questions arise as to what the implications are for face-to-face interactions within couple relationships (Leggett \& Rossouw, 2014). 
Review of related literature on marital conflicts shows non negligible contribution of recently developed technologies in marital conflicts. Hertlein and Ancheta (2014) stated that $33 \%$ of divorce cases mentioned Facebook in 2011.Similarly, Kerkhof, Finkenauer, \& Muusses (2011) found that people who spend more time on the Internet report spending less time with family and friends. Individuals can develop strong relationships with mobile phones, which combine communication, computing abilities, and personalized applications and the advancement of technology, particularly with the mobile phone, has introduced a process of distraction and separation in couple relationships (Leggett \& Rossouw, 2014).

Supporting this, $\operatorname{Epp}(2016)$ found the addictive behavior to evolve from overuse of social networking for young people influencing their relationships with others (Epps, 2016). This addiction, all forms of addictions, negatively affects individuals such as problems in passing of life and marital relationship, changing the style of life, spending more time on the Internet, lack of attention to family members and ignorance of family and friends, these are among the consequences of the Internet addiction which can affect the reduction of marital satisfaction (Mojaz, Reza, Paydar, \& Ebrahimi, 2015).

Television, as one of the out of technology has also its own contribution on couple's relation in a family since it takes the time they may spend together. Cultivation theory further suggests that television is responsible for shaping, or 'cultivating' viewers' conceptions of social reality (Moon, 2003). Similarly,(Aubrey et al., 2013) elaborates the positive association of TV with several dysfunctional relationship beliefs, including the beliefs that (a) men and women differ substantially in personalities and relationships needs, (b) it is critically important to find a perfect sexual partner/experience, and (c) partners can change neither themselves nor the qualities of their relationships

\subsection{Statement of the problem}

In a longitudinal study done by Kerkhof et al ( 2011) found that using the Internet for entertainment negatively affected the quality of both romantic and best-friend relationships over time . Hertlein and Ancheta (2014) found that if a partner's computer is left accessible or a spouse's password is known, partners will often engage in investigatory behaviors that lead to the discovery of infidelity activities. Maintaining a satisfying relationship can be more difficult if the individual had a negative past experience on a social networking site (Kerkhof et al., 2011). Sharaievska (2012) showed that leisurerelated conflicts could be more stressful than conflicts related to child rearing and finances.

In general knowing the relationship between technology usage and marital conflict is a very crucial since technology is now integrated into everyday living. Despite of the fact that young married couples are almost at the age of adolescence and early adult range those who are highly used technologies it could be the source of their conflict. Additionally, Even though many researches had been conducted on the role of technology in romantic relationship and in marital satisfaction, to the researcher knowledge review there is no research on the relationship between technology usage and marital conflict.

Based on the statement of the problem the following research questions were designed:

- What is the nature of technology usage among young married couples?

- What is appropriate technology usage among marital couples?

- What are the common causes of marital conflicts as a result of technology usage?

- What is the level of the extent of association between technology usage and marital conflict? 


\subsection{Objectives of the study \\ 1.2.1 General objective}

To assess the relationship between technology usage and marital conflict among young married couples in Jimma town.

\subsubsection{Specific objectives}

- To identify the nature of technology usage among young married couples.

$\bullet$

- To determine technology usage and its appropriateness among marital couples.

- To investigate the common causes of marital conflicts as a result of technology usage.

- To investigate the level of the extent of association between technology usage and marital conflict.

\section{Research methods}

\subsection{Research design}

A mixed research design was employed for this research. Since the study employed both quantitative and qualitative research methods.

\subsection{Target population}

The target population of this study was young married couples in Jimma town. Because technology usage are more familiar to young married couples than old married couples and to get the relevance and proper response in related to technology usage since they are rich with the information.

\subsection{Sample size} and wife.

The sample size for this research was 198(which means 99 males and 99 females that are husband

\section{$2.4 \quad$ Sampling techniques}

Simple random sampling which is lottery method was employed to select participants. Simple random sampling was selected to give equal chance for the participants. In this study, the selected sample size were obtained from the population formally established marriage and registered in 2013-2016 by Jimma town Social Vital Events Registration Agency. The total population of the study was 394 couples which includes 197 males and 197 females. To get sample of the obtained couples Slovin's sample size determination formula (Yemane, 1967) was used. The formula is written as $\mathrm{n}=\mathrm{N} /\left(1+\mathrm{N}^{*} \mathrm{e}^{2}\right)$ where $\mathrm{n}=$ Number of samples, $\mathrm{N}=$ Total population (394) and $\mathrm{e}=$ Error tolerance. Based on sample size determination formula, the calculated sample size was 198, at $95 \%$ confidence level and 0.05 precision levels. Accordingly, 198 samples (99 males and 99 female participants) were selected using simple random sampling method from the total of 394 registered couples. Finally, the researcher contacted these 198 couples using their addresses. 


\subsection{Instrument of data collection}

A self-administered questionnaire modified from standardized scales test was adapted according to the context of the research and individual interviews were used for data collection. Both open-ended and close-ended questionnaire were used for data collection. For the degree of association between technology usage and marital conflicts, the standardized Likert scales questionnaire was used and adapted in the context of the research. Semi-structured interview was used to collect data about the appropriateness of technology usage in marital relationship, common causes of marital conflict as a result of technology usage, the relationship between technology usage and marital conflict.

\subsection{Procedure of data collection}

In the process of data collection, first, a written letter from Jimma University College of education and behavioral science was obtained. The purpose and importance of the study was discussed with Jimma town social vital events registration agency and how to access participants.. Written consent was processed within the couples. On the initial meeting, the purpose and importance of the study was explained for the participants and there was a deep individual interview process. The questionnaire was prepared in English language and translated into local language (Amharic/Afan oromo) and distributed for them. Data was collected from these young married couples with the assistance of graduates two other graduate students of the department.

\subsection{Methods of data analysis}

Data were analyzed both quantitatively and qualitatively. Quantitatively data was analyzed by statistical analysis of Pearson's correlation methods by using statistical package for social sciences (SPSS) version 20.0 to investigate the level of the extent of association between dependent variable and independent variables. Descriptive statistics (such as percentage, frequency and pie charts) were used in order to enhance and make meaningful analysis and interpretation of the research output. On the other hand, qualitatively data was analyzed by using word description and direct quotation of information obtained by semi structured individual interview.

\section{Results and Discussion}

General characteristics of the participants

As it was discussed above, equal men and women were included in the study since the target population of the study had been married couples including married men 99(50\%) and married women 99(50\%). Regarding the age structure of the participants, the majority of the participants i.e. $65.2 \%$ were found in the age range of 25-34 years. This result showed that, most of the sample participants were almost young married couples.

To use technology properly education and skills are important things to relative and experience us with different technology access. From the sample participant of 198, 28(14.1\%) of participants were able to read and write which means they completed up to grade eight but they were not join their high school class, whereas the majority $69(34.8 \%)$ of participants had completed certificate and diploma. This implies that, they could perform well and familiar with different activities of technology.

Regarding the religion of the participants, out of 198, 53(26.8\%) were from orthodox religion, $112(56.6 \%)$ were from Muslim, 32(16.2\%) were from protestant religion and 1(.005\%) was from Catholic religion. This implies that the majority $(56.6 \%)$ of couples investigated in this study followed Islam religion, whereas a small number of participant which mean 1(.005\%) followed Catholic religion individually. 


\section{The nature of technology usage among young married couples}

The majority $(47.5 \%)$ of male couple participants enjoyed television than mobile and Facebook followed by (27.3\%) mobile and (25.3\%) Facebook respectively. These figure shows that couples and their spouse's technology preferences which is the majority of male couples $(47.5 \%)$ were mostly used television, and the majority of their female spouse preferred Facebook 41.4\%. This implies that there was incongruence between the couples in the need of technology usage that may leads to disagreement/marital conflict between the couples. Because if couples need technology usages, it is not match when one want to relax with his/her spouse while the other may want to stay on using Facebook or watch television, dramas, sports and etc.

Data collected from the participants also showed sex differences in relation with daily Facebook usage. Accordingly, 52(55.9\%) of male couples and 36(46.2\%) of female couples sign into their Facebook account daily. This difference could be due to the gender role in families. Because women stayed more time with children, think and prepare about what to eat and the likes. Since females are more responsible for home making activities especially in Ethiopian context. Tang and Cousins (2005) as cited in Thanuskodi (2013) further supported that women are still mainly responsible for domestic labor and childcare.

\section{Relationship status of couples on Facebook}

The majority (62.6\%) of participant's relationship status on Facebook showed single relationship whereas, 22(12.9\%) of participants relationship status on Facebook showed married and the rest showed different relationship status. This indicated that, couples relationship status didn't show their real situation relationship status. When these couples were asked for the motive behind hiding their marital status, they reported the needless to do so. However, making such like false profile on Facebook by itself may indicate need for further relationship and opens a door for conflict that may arise in marital relation. Similarly, with the above result the previously conducted research stated that, disclosing oneself as single may signal that you are actively pursuing relationship possibilities or that you are open to the idea of dating, it could also signal that you are available for casual hook ups. In one study, disclosing oneself as "Single" on Facebook was rated as the top method for eliciting contact from potential partners (Larson, 2014).

The majority $73(42.7 \%)$ of participants responded that they stayed three to five hours on Facebook in a typical week, followed by 54(31.8\%) of couples stayed on Facebook in a week. Whereas, the minimum 16(9.1\%) were spent on Facebook in a typical week for $>10$ hours. This indicated that, even if marital conflicts might cause due to several factors, staying more times on Facebook could also be included in the major factor to raised during marital conflicts between the couples. In the same ways, Darvell et al. (2011) as cited in (Farrugia, 2013) found in their study that the more time spent on Facebook or SNS the more time a partner's behavior would be monitored. Farrugia (2013) concluded that this ease of information into the online world of Facebook in daily life directly caused more issues than good. The majority $53.8 \%$ of participants were formed unhealthy relationship with others they meet online. This implies that, most of couple's relationship goes beyond their marital relationship, which may play a great role in raising couple's unhealthy marital relationship/conflicts as of Facebook usage.

The result also revealed that, the majority 111 of total Facebook usage participants which means, $64.9 \%$ of couples didn't share one another's Facebook account passwords, 12(7\%) of participants shared each other's Facebook account passwords whereas, the rest 25(14.6\%) and 23(13.5\%) of participants were partially share their passwords. This indicates that the information and chats they shared with others could have an impact on their marital relationship; this is the only reason that limits couples from sharing Facebook accounts password one another. Similarly research showed that, hiding passwords one another between the couples were decreased the trust should have to exist between them. Because, according to Epps (2016) sharing passwords is first and foremost, an extension of trust in a relationship. Your partner will trust you a whole lot more if you are comfortable enough to share your passwords with them. It 
shows you have nothing to hide and are committed to the relationship a hundred percent. Another benefit of sharing your password with your partner is that you are less likely to engage in any form of indiscretions online if you know your partner has access to your accounts (Epps, 2016).Concealing passwords one another by itself psychologically makes the couples to develop doubt of one another that gradually creates a gap/ marital conflict in their marital relationships.

Table 4.1. Knowing who is calling on their spouse's mobile phone

\begin{tabular}{cccc}
\hline & & Frequency & Percent \\
\hline Do you & Yes & 88 & 44.4 \\
ask who & No & 72 & 36.4 \\
\hline $\begin{array}{l}\text { Is calling } \\
\text { to your }\end{array}$ & I check myself secretly & 38 & 19.2 \\
spouses & Total & 198 & 100 \\
\hline
\end{tabular}

Source: Own field survey, 2017

As indicated above in table 4.1, the majority $88(44.4 \%)$ of the total sample participants responded that they asked their spouses who is calling to their mobile phone. This implies that they suspect something if their opposite sex men and women may call to their spouses; to identify this, the majority of couples asked their spouses. Previously conducted research also shows that the access to their partner's information may lead to a higher degree of jealousy based on the information one is exposed to. Romantic jealousy can create negative thoughts about a partner and the relationship as a whole (Farrugia, 2013).

Table 4.1.1. Secretly read the sms messages on once spouse's mobile phone

\begin{tabular}{lll}
\hline & Frequency & Percent \\
\hline Yes & 105 & 53 \\
No & 93 & 47 \\
Total & 198 & 100 \\
\hline
\end{tabular}

Source: Own field survey, 2017

From the above table 4.1.1, 105(53\%) of the total sample of participants reported that they secretly read the sms messages sent to their spouse's mobile phone, whereas 93(47\%) of participants responded as they did not check the sms messages sent to their spouse's mobile phone. As we can understand from this table, the majority $53 \%$ of couple participants checked sms messages sent to their spouse's mobile phone. This implies that most of the couple participants were under the pressure of suspecting their spouses due to their mobile usages. Continuous suspecting of one another may minimize the connection between the couples. On the other hand, if one of the couple tried to read secretly their spouses SMS messages and their spouses saw them, it could be the beginning of conflict between them.

In relation with television watch, the majority (59.6\%) of couples watch lonely after his/her spouses gone sleep. The occurrence of mismatch in the need of couples watching television had its own side effect on couple's relationship. Because one may want to enjoy with his/her spouses but the other may want to enjoy with a television. Watching television alone among young married couples also led couples to develop loneliness by limiting their good communication, time to couples were staying together and regular activities that must be in every marriage institutions. These in turns might lead the couples to marital conflicts. Similarly the study also revealed that, watching television affects people by taking time away from other activities, such as social interaction, sport, and reading (Moon, 2003). By consuming television individually, this leads to social isolation, household activities become individualized and thus, there is a growing privatization within the household. In turn, this results in a drastic decrease of communication and social interaction within a household (Corcoran, 2012). 
Couple's preference for the types of programs they want to attend was also found to be somewhat different as found out in this study. For example, in this study $41.4 \%$ of male couples preferred sports program compared to $35(35.4 \%)$ female couples that preferred TV programs that focus on religious issues. The majority of male and female couples were stayed long time on television which is for more than five hours per a day.

The appropriateness of technology usages among young married couples

The qualitative result of this study revealed that, the importance of technology when couples used in an appropriate ways is high.As they,decrease time and distance problem,give information, and easen life hazards. Regarding mobile usage; Mobile call gives us both a chance to really say what we want to and know we've been heard, "offers time to think about a response before stating it (especially text message), able to think before you react, taking time to prepare a response and Mobile was one key way in which apologies could be exchanged. (e.g sorry and love you text).

Television helps couples to get new information, knowledge and the like. Television watching feels you free when you sit down and watch television right after getting home from work; to pass the time or for relaxation. It also helps couples to be connected to their God.

The common causes of marital conflicts as a result of technology usage

Qualitative survey showed that, time spent on those technologies, issue of trust between couples, the issues of money wastage, the time when, where, how and what the couples to use these technologies was the major common causes raised in conflicts between couples. Similarly, potential challenges of technology use on intimate relationships include: miscommunication as a result of lacking nonverbal communication, more uninhibited behaviors, and access to opportunities for infidelity, access to pornography, monitoring one another, relationship abuse perpetration, overuse, and distraction (Epps, 2016). If high use of technology influences trust negatively in relationships, this negative impact likely spills over into other relational ethics components (Epps, 2016). Previous research findings that trust may be disrupted in relationships where technology use is high (Epps, 2016).

The relationship between technology usage and marital conflicts Table 4.1.2. Technology usage and marital conflicts

\begin{tabular}{|c|c|c|c|}
\hline & & Facebook usage & Marital conflicts \\
\hline \multirow{3}{*}{ Facebook usage } & Pearson correlation & 1 & $.788^{* *}$ \\
\hline & Sig.(2-tailed) & & .000 \\
\hline & $\mathrm{N}$ & 171 & 171 \\
\hline \multicolumn{4}{|c|}{$* *$. Correlation is significant at the 0.01 level (2-tailed). } \\
\hline \multirow{4}{*}{ Mobile usage } & & Mobile usage & Marital conflicts \\
\hline & Pearson correlation & 1 & $.642^{* *}$ \\
\hline & Sig.(2-tailed) & & .000 \\
\hline & $\mathrm{N}$ & 198 & 198 \\
\hline \multicolumn{4}{|c|}{ **. Correlation is significant at the 0.01 level (2-tailed). } \\
\hline \multirow{4}{*}{ Television watch } & & Television watch & Marital conflicts \\
\hline & Pearson correlation & 1 & $.630^{* *}$ \\
\hline & Sig.(2-tailed) & & .000 \\
\hline & $\mathrm{N}$ & 188 & 188 \\
\hline
\end{tabular}

Pearson product moment correlation coefficient showed that, there is strong positive relationship between Facebook usage and marital conflict with $(\mathrm{r}(171)=0.788, \mathrm{P}=0.000 \mathrm{p}<0.01)$. Hence, we can understand that high Facebook use may mean high marital conflict since Facebook usage can predict 
marital conflict and also the relationship between Facebook usage and marital conflicts are statistically significant.

The result of relationship also indicated that, mobile usage and marital conflict have significant positive relationships with $\mathrm{r}=0.642, \mathrm{P}=0.000<0.01$. This means that, these two variables can increase or decrease together. Thus, mobile usage can predict marital conflicts. The above correlation result also indicates that there is a positive strong relationship between mobile usage and marital conflicts.

Pearson product moment correlation coefficient also demonstrates that, there is strong positive relationship between television watch and marital conflicts with $(\mathrm{r}(188)=0.63, \mathrm{P}=0.000 \mathrm{p}<0.01)$. Hence, we can deduce that high television watch may mean high marital conflict since television watch can predict marital conflict.

\section{Conclusion}

Based on the findings of the study, the following conclusion was drawn:

$>$ The study showed Facebook, television, and mobile to be the most common technologies that couples use most of the time. As a result, these technologies share the time they have for one another, the couple's time of staying together, their leisure time, their time of discussion about their regular tasks and their families' condition, and the like that leads the couples to marital conflicts.

$>$ The other result is technology is very crucial and appropriate things in marital relationship only when the couples used technology in appropriate ways and at appropriate time; these means when the couples used technology for the purpose of gaining information, give and receives messages to the only concerned bodies, entertainment, and for gaining knowledge using technology is appropriate in marital relationship. But going beyond those purposes of technology usage are pushes couples to marital conflicts.

$>$ The result also shows the relationship between technology usage and marital conflicts are strong positive relationship. This implies that, technology usage and marital conflicts can increase or decrease together. Thus, technology usage can predict marital conflict.

$>$ The common causes of technology usage and marital conflicts are time spent on those technologies, issues of trust between couples, issues of money and the time when couples have to use these technologies. Because, as one of the couples used technology for long period of time their spouses developed the feelings of distrust each other. Hence, using technology needs a time and money it minimizes the trust between couples and the time they have to stay with each other. Accordingly, technology usage may affect couples marital relationship.

\section{Recommendation} forwarded.

Based on the findings and conclusions of the study, the following recommendations are

Different organizations such as welfare offices, NGOs and religious organizations should have to assign trained family and marriage counselors and social workers.

There is need for family and marriage counselors to create awareness for married people on the existence of marital conflicts through the means of technology usage and how, when, where, and what the 
couples have to use technology to maintain marital satisfaction. This awareness can be done through seminars, workshops and different social Medias.

\section{References}

Aubrey, J. S., Rhea, D. M., Olson, L. N., \& Fine, M. (2013). Conflict and Control: Examining the Association Between Exposure to Television Portraying Interpersonal Conflict and the Use of Controlling Behaviors in Romantic Relationships. Communication Studies, 64(1), 106-124. https://doi.org/10.1080/10510974.2012.731465.

Corcoran, M. (2012). the Impact of New Media Technologies on Social Interaction in the Household. Electronic Culture and Social Change, (April), 48.

Epps, C. (2016). an Exploration of How Technology Use Influences Relational Ethic, (April).

Farrugia, R. C. (2013). Facebook and Relationships : A Study of How Social Media Use is Affecting Long-Term Relationships. Rochester Institute of Technology RIT Scholar Works, 50.

Hertlein, K. M., \& Ancheta, K. (2014). Advantages and Disadvantages of Technology in Relationships : Findings from an Open-Ended Survey Advantages and Disadvantages of Technology in Relationships : Findings, 19(11), 1-11.

Kerkhof, P., Finkenauer, C., \& Muusses, L. D. (2011). Les cons??quences relationnelles d'un usage compulsif d'Internet: une ??tude longitudinale aupr??s de nouveaux mari??s. Human Communication Research, 37(2), 147-173. https://doi.org/10.1111/j.14682958.2010.01397.x.

Larson, E. M. (2014). Relationship status disclosure : Associated correlates and behaviors.

Leggett, C., \& Rossouw, P. (2014). The Impact of Technology Use on Couple Relationships: A Neuropsychological Perspective. International Journal of Neuropsychotherapy, 2(1), 44- 
99. https://doi.org/10.12744/ ijnpt.2014.0044-0099.

Mojaz, Z. H., Reza, M., Paydar, Z., \& Ebrahimi, M. E. (2015). the Relationship Between the Internet Addiction and the Use of Facebook With Marital Satisfaction and Emotional Divorce Among Married University Students, 5, 709-717.

Moon, K. (2003). Cultivation Theory Definition, 1-11. https://doi.org/doi:10.1111 /b.9781405131995.2008.x.

Thanuskodi, S. (2013). Gender Differences in Internet Usage among College Students : A Comparative Study.

\section{Copyrights}

Copyright for this article is retained by the author(s), with first publication rights granted to the journal.

This is an open-access article distributed under the terms and conditions of the Creative Commons Attribution license (http://creativecommons.org/licenses/by/4.0/). 